\section{The Glow-worm}

ALTHOUGF in several Natural History Encyclopædias Scotland is excluded from the list of countries containing the glowworm, I can aver that in Nithsdale and in the parish of Tynron, Dumfriesshire, they are quite plentiful. Yestreen, in Tynron, I observed one, to my surprise, shining by the wayside. It is a proof of the mildness of the season, no doubt, as I never saw them in December before, but have seen them several times as late as October.

When carrying one home one evening in my open hand it contracted itself and leaped out of my hand. This is a power they possess which I have seldom seen mentioned. The light in winter is much feebler than in summer, but the time was ten o'clock, or more than six hours after sunset that I saw it, whereas I never witnessed the glow of one in summer so long after dusk. Some that died with me forcibly reminded me of the poet's remark that between the rose's shadow and the very rose there was not a greater contrast than that between "the dead glow-worm and the worm that glows." J. SHAw

Tynron Schoolhouse, Dec, 26, 1875

\section{OUR ASTRONOMICAL COLUMN}

ENCKE'S COMET.-By the calculations of Encke and others who have continued them, we are in possession of the dates of perihelion passage of the comet which bears his name, from 1786 to 1875 . If these be arranged and the intervals taken between the successive dates, it will be found that in the course of these ninety years the effect of perturbation has not changed the period of two successive revolutions by a hundredth part. The revolution I $819-1822$ was $10 \cdot 1$ days longer than that between $18 \times 5$ and 1819 , and the revolution $I 845-1848$ was II'I days shorter than the preceding one, and these are the largest variations exhibited. In the same period, the longest interval between two successive arrivals at perihelion is 1215.6 days, $1842-1845$, and the shortest I200.2 days, I 868-187I.

In aphelion the distance of the comet from the orbit of the planet Jupiter by the elements of 1875 is 0.915 , too great to allow of any violent perturbation. In about $123 \frac{1}{2}^{\circ}$ heliocentric longitude, and $6^{\circ} .50^{\prime}$ north of the plane of the ecliptic the comet approaches the orbit of Mercury within 0.038 ; to bring the bodies into closest possible proximity it is necessary that the planet shall arrive at perihelion $12 \frac{1}{2}$ days before the comet, and we know that a very close approach to this condition took place in November I848, whereby, on the 22 nd of that month, the comet was brought within 0.0378 from the planet, a distance of about fifteen times that which separates the moon from the earth. A close encounter with Mercury appears hardly possible before the year I904.

If the orbit of Encke's comet was fixed within its present comparatively restricted limits by planetary attraction, it seems quite as likely that this may have been occasioned by an extremely close approach to Mercury as that Jupiter at some distant period should have been the disturbing agent.

OCCUltations of the Planet SATURN.-We are not very fortunate in this country as regards the circumstances of the batch of eleven occultations of Saturn by the moon, which take place in successive lunations, commencing on the 22nd of March next ; the only one visible in England being that on the morning of the 7 th of August, and this will be a daylight phenomenon, the sun rising, at Greenwich, more than half an hour before the immersion. Of the ten occultations of the planet in 1870 , three were visible here, and the occultations of that year possessed greater interest from the circumstance of the wider opening of the rings, than those of 1876 are likely to be attended with, wherever witnessed. The near approach of Saturn to the moon's limb between I and 2 A.M. on July II, as viewed at Greenwich, does not appear to be converted into an occultation in any part of these islands.
While writing upon occultations, a word may be said of the close approach of the planet Jupiter to the star $\beta^{1}$ Scorpii, on the morning of February 28 , which is entered as a possible occultation in the American Ephemeris. $\beta$ Scorpii is a double star, the components being of 2 and $6 \frac{1}{2}$ magnitudes, distance about $13^{\prime \prime}$, or according to the "Melbourne General Catalogue" of 1870 , the smaller star follows in R.A. 0*40s, and is $\mathrm{II}^{\prime \prime} \cdot 95$ north of the brighter one. The apparent position of $\beta^{1}$ Scorpii on Feb. 27 is in R.A. 15 h. $58 \mathrm{~m}$. $144^{\prime} 4 \mathrm{Is}$, and N.P.D. $109^{\circ} 28^{\prime} 2^{\prime} 1^{\prime \prime}$. The Nautical Almanac place of Jupiter, which is from Bouvard's Tables, will probably require a correction of about $+0^{\circ} 90$. in R.A., in which case the conjunction of planet and star would take place a few minutes after meridian passage at Greenwich on the morning of the 28 th or about $5 \mathrm{~h}$. $4 \mathrm{om}$. A.M., and the north limb of Jupiter is brought close upon the star, but there still seems likely to be a difference of some three or four seconds in N.P.D., by which small quantity the star may escape occultation. The companion is too far north to be occulted. This judgment is formed by a comparison of the latest published corrections of Bouvard, given by the Greenwich observations, and the differences between Le Verrier and Bouvard at the end of 1877 .

A close approach of Jupiter to this star is recorded by the Chinese as early as the year A.D. 73 ; on the 12th of February the planet was very near the star, four days afterwards the star was seen having been previously hidden by the superior brightness of Jupiter; and the Chinese also report that the planet which had been very near to $\beta$ Scorpii A.D. 5 I2, January 12, occulted it on the I 7 th of April following.

\section{PROF. STOKES ON THE EARLY HISTORY OF SPECTRUM ANALYSIS}

$T \mathrm{HE}$ following extract from a letter, relating to the early history of spectrum analysis, from our highest English authority on physical optics, cannot fail to interest, apart from its intrinsic importance, a wide circle of readers. I have therefore obtained permission from. Prof. Stokes to forward it to NATURE.

\section{T. L. WHITMELI}

"CAMBridge, Dec. 23, 1875

"I felt that the coincidence between the dark D of the solar spectrum and the bright $D$ of a spirit-lamp with salted wick could not be a matter of chance; and knowing as I did that the latter was specially produced by salts of soda, and believing as I did that even when such were not ostensibly present, they were present in a trace (thus alcohol burnt on a watch-glass and a candle snufied close, so that the wick does not project into the incandescent envelope, do not show bright D), I concluded in my own mind that dark $\mathrm{D}$ was due to absorp. tion by sodium in some shape. In what shape? I knew that such narrow absorption-bands were only observed in vapours; I knew that as a rule vapours agree in a general way with their liquids or solutions as to absorption, save that in lieu of the capricious absorption of the vapour, we have a general absorption attacking those regions of the spectrum in which the vapour-bands are chiefly found. Hence as the sodium compounds, chloride, oxide, \&c., are transparent, I concluded that the absorbing vapour was that of sodium itself. Knowing the powerful affinities of sodium, I did not dream of its being present in a free state in the flame of a spirit-lamp; and so I supposed that the emitting body in the case of a spirit-lamp with salted wick was volatilised chloride of sodium, capable of vibrating in a specific time, or rather two specific and nearly equal periods, by virtue of its sodium constituent; but that to produce absorption the sodium must be free. I never thought of the extension of Prevost's law of exchanges from radia. tion as a whole to radiation of each particular refrangi- 
bility by itself, afterwards made by B. Stewart; and so I failed to perceive that a soda flame which emits bright $\mathrm{D}$ must on that very account absorb light of the same refrangibility.

"When Foucault, whom I met at dinner at Dr. Neil Arnott's, when he came to receive the Copley Medal in 1855 , told me of his discovery of the absorption and emission of $D$ by a voltaic arc, I was greatly struck with it. But though I had pictured to my mind the possibility of emitting and absorbing light of the same refrangibility by the mechanism of a system of piano strings tuned to the same pitch, which would, if struck, give out a particular note, or would take it up from the air at the expense of the aërial vibrations, I did not think of the extension of Prevost's theory, afterwards discovered by Stewart, nor perceive that the emission of light of definite refrangibility necessitated (and not merely permitted) absorption of light of the same refrangibility.

"Reviewing my then thoughts by the light of our present knowledge, I see that my error lay in the erroneous chemical assumption that sodium could not be free in the flame of a spirit-lamp; I failed to perceive the extension of Prevost's theory, which would have come in conflict with that error.-Yours sincerely, (Signed)

"To Chas. Whitmell, Esq."

"G. G. STOKES

"P.S., Dec. 31.-As Sir Wm, Thomson has referred in print to a conversation I had long ago with him on the subject, I take the opportunity of describing my recollection of the matter.

"I mentioned to him the perfect coincidence of bright and dark $D$, and a part at least of the reasons I had for attributing the latter to the vapour of sodium, using I think the dynamical illustration of the piano strings. mentioned also, on the authority of Sir David Brewster, another case of coincidence (as was then supposed, though it has since been shown to be only a casual near agreement) of a series of bright lines in an artificial source of light with dark lines in the solar spectrum, from which it appeared to follow that potassium was present in the sun's atmosphere. On hearing this Thomson said something to this effect: 'Oh then, the way to find what substances are present in the sun and stars is to find what substances give bright lines coincident with the dark lines of those bodies.' I thought he was generalising too fast; for though some dark lines might thus be accounted for, I was disposed to think that the greater part of the non-terrestrial lines of the solar spectrum were due to the vapours of compound bodies existing in the higher and comparatively cool regions of the sun's atmosphere, and having (as we know is the case with peroxide of nitrogen and other coloured gases) the power of selective absorption changing rapidly and apparently capriciously with the refrangibility of the light.

"If (as I take for granted) Sir William Thomson is right as to the date $[1852]$ when he began to introduce the subject into his lectures at Glasgow (Address at the Edinburgh Meeting of the British Association [1871], page xcv.), he must be mistaken as to the time when I talked with him about Foucault's discovery, for I feel sure I did not know it till 1855 . Besides, when I heard it from Foucault's mouth, it fell in completely, with my previous thoughts.

"I have never attempted to claim for myself any part of Kirchhoff's admirable discovery, and cannot help thinking that some of my friends have been over zealous in my cause. As, however, my name has frequently appeared in print in connection with it, I have been induced to put on paper a statement of the views I entertained and talked about, though without publishing.

"In ascribing to Stewart the discovery of the extension of Prevost's law of exchanges, I do not forget that it was re-discovered by Kirchhoff, who, indeed, was the first to publish it in relation to light, though the transition from radiant heat to light is so obvious that it could hardly fail to have been made, as in fact it was made, by Stewart himself (see 'Proceedings of the Royal Society,' vol. x. p. 385). Nor co I forget that it is to Kirchhoff that we owe the admirable application of this extended law to the lines of the solar spectrum."

\section{SCIENCE IN THE ARGENTINE REPUBLIC *}

THE fourth part of the Bulletin of the National Academy of Sciences recently founded at Cordova, in the Argentine Republic, completes the first volume of this remarkable work, of which we have previously given some account to our readers. $\dagger$ The present part is mainly occupied by the conclusion of a long article upon the vegetation of the little known province of Tucuman, in the interior of the Republic, by Dr. Hieronymus, commenced in a former number. This is based upon the observations made by the author during a long and extensive scientific journey in that province, and upon the collections amassed by Dr. Lorentz in the same districts in $187 \mathrm{I}$ and 1872 , which have been mainly deternined by Prof. Grisebach, of Göttingen. A second important article is by Dr. D. A. Döring, and treats of the land and freshwater Molluscs of the Argentine Republic, arnongst which are a considerable number of new species, and several interesting novel forms discovered by the author. A third memoir, from the pen of Dr. Burmeister, treats of the abnormal Hymenopterous insects of the Linnean. genus Mutilla, and forms a complete monograph of the native species of this group, which will be very acceptable to entomologists. By the chronicle appended to the number, we learn that the strife which has prevailed between the Director of the Academy and the six German professors originally imported for its constitution has terminated in the signal defeat of the latter. After the expulsion of about half the number, the remainder resigned, and their places have been filled by other professors from the same country, whom we trust Dr. Burmeister will find more tractable. That they are full of work is evident by the contributions to science already published in the present volume, upon the successful completion of which we heartily congratulate the energetic and illustrious Director of the Academy of Natural Sciences of the Argentine Republic.

\section{SOME UNSOLVED PROBLEMS IN THE MANAGEMENT OF THE MARINE AQUA- RIUM}

$T T$ would be fatal to further progress in that direction in which so much has been achieved during the last ten years, if the zoological conditions of even the most successful of existing marine aquaria were to be blindly accepted as incapable of improvement, and especially if further experiment in reference to the vexed question of aerration were to be barred by the assumption that any one of those rival systems which are typified in the practice of Brighton, Sydenham, or any other similar establishment, is necessarily the best which can be attained.

More discussion than it has yet received is due to the broad question whether the total or almost total exclusion of vegetation from public aquaria is based on necessity or philosophy; whether artificial may not be advantageously supplemented by this most natural and automatic mode of aëration ; and the further question remains, to what extent must the conditions of the aquarium be modified, as regards circulation and introduction of air, in order to render practicable the establishment and maintenance of a healthy vegetation, if the propriety of its introduction

* "Boletin de la Academia Nacional de Ciencias exactas existente en la Universidad de Cordova." Entrega iv. (Buenos Ayres, I875.)

+ See NA.ture, vol, xi. p. 253 . 